\title{
Topical Stick Dosage Form
}

National Cancer Institute

\section{Source}

National Cancer Institute. Topical Stick Dosage Form. NCI Thesaurus. Code C149421.

Solid preparation, usually rod-shaped or conical, intended for application to the skin to obtain a local effect. Cutaneous sticks may consist of the active substance(s) alone or dissolved or dispersed in a suitable basis. 